May 2000. To appear in R.M. Harnish and Istvan Kenesei (eds) Festschrift for Ferenc Kiefer. John Benjamins Publishing Company, Amsterdam. (Final revised version)

\title{
Some Puzzles of Predicate Possessives ${ }^{1}$
}

\author{
Barbara H. Partee, University of Massachusetts, Amherst \\ Vladimir Borschev, VINITI, Moscow
}

\section{Background: Possessives and the argument-modifier distinction in NPs.}

Possessive constructions like John's teacher, John's team, John's cat, friend of John's offer an interesting test-bed for the argument-modifier distinction in NPs, both in English and cross-linguistically. Many, perhaps all, possessives seem to have some properties of arguments and some of modifiers, but some seem more argument-like and some more modifier-like. Recent proposals by Jensen and Vikner (1994), Vikner and Jensen (ms.1999), Partee and Borschev (1998), Borschev and Partee (1999a,b) analyze all possessives as argument-like, a conclusion we are no longer sure of. It is not easy to settle the question of whether there is a substantive difference between these two "roles" of possessives, and it may well be the case that all or many possessives play both roles at once.

One central question about possessive constructions, then, is the following: Are all, some, or no possessives arguments of nouns, and if so, which ones (and how can we tell?), and of what kind, and at what 'level' of analysis?

Within this larger question, we discuss here a relevant narrower question: Do predicate possessives provide strong evidence against a unified treatment of all possessives as arguments?

\subsection{Possessives/genitives and related constructions.}

The terminology surrounding "possessives" and "genitives" is confusing, since the correspondences among morphological forms, syntactic positions, grammatical relations, and semantic interpretations are complex and debated, and vary considerably across languages. For clarification, let us distinguish at least the following: ${ }^{2}$

a. Possessive pronouns: E. my, his; R. moj 'my', ego 'his'; E. predicative forms mine, his and postnominal forms of mine, of his.

\footnotetext{
${ }^{1}$ The authors wish to thank many colleagues for suggestions and discussion, especially Sigrid Beck, Manfred Bierwisch, Wayles Browne, Johannes Dölling, Irene Heim, Per Anker Jensen, Hans Kamp, Tony Kroch, Godehard Link, Elena Paducheva, Ekaterina Rakhilina, Carl Vikner, Sten Vikner, Ilse Zimmermann, and an anonymous referee. The first author presented this material in October 1999 at the second annual MIT-UMass -UConn Semantics Workshop at MIT, and we thank the participants for helpful discussion. Parts of it were presented by the first author at a Graduiertenkolleg Klausurtagung held by the Linguistics Department of the University of Stuttgart in Kleinwalsertal, Austria, and by both authors in Berlin and in Munich in June 1999.

This material is based upon work supported by the National Science Foundation under Grant No. BCS9905748. Any opinions, findings, and conclusions or recommendations expressed in this material are those of the authors and do not necessarily reflect the views of the National Science Foundation.

This paper is dedicated with affection to our oldest joint friend Ferenc Kiefer.
}

${ }^{2}$ We use English and Russian for illustrative purposes, abbreviated below as E and R. 
b. English "Saxon genitives": John's, and the postnominal Saxon genitive of John's.

c. English PP with of + Acc.

d. Russian postnominal genitive NP: Mendeleeva 'of Mendeleev', tigra 'of a/the tiger'

e. Russian prenominal possessive: Mašin dom 'Masha's house'.

Some of the problems of the semantics of possessives affect all of these, while some of the problems require making distinctions. Very similar problems arise in corresponding constructions in many other languages, and related problems arise with the English verb have and its lexical and constructional counterparts in other languages (Freeze 1992, Landman and Partee 1984, Szabolcsi 1994, Jensen and Vikner 1996, Partee 1999b). The present work concerns the possible need for a distinction between possessives as modifiers and possessives as arguments, and the role that predicate possessives may play in resolving that issue.

One starting point is the following data from Partee (1983/97: 464):

(a) John's team

(b) A team of John's

(c) That team is John's

(2) (a) John's brother

(b) A brother of John's

(c) (\#) That brother is John's

(a) John's favorite movie

(b) A favorite movie of John's

(c) (\#) That favorite movie is John's

Informally, a unified interpretation of genitive phrase "John's" that applies to all of these cases is that the genitive phrase always expresses one argument of a relation, for which we will use the descriptive term "genitive relation", following Jensen \& Vikner (1994). But the relation can come from any of three sources: (i) the context, as in (1) ("plays for", "owns", "is a fan of", etc.); this happens when the noun is a plain 1-place predicate; (ii) an inherently relational noun like "brother"; (iii) an inherently relational adjective like favorite. The puzzles include these: can (and should) examples (1a) and (2a) be given a uniform analysis, and if so, how? Or does the genitive construction combine differently with plain and relational nouns, and if so, are these differences predictable from some general principles? Should the first case be split into two distinct cases, one being a default preference of the "genitive" construction itself for a genitive relation in the family of "owns", "possesses", "controls", possibly with a distinct syntactic source? The examples in (3) show that argument-like genitives cannot always simply be analyzed as complements of a lexical noun, since it is the whole $\mathrm{N}$-bar favorite movie that provides the relation of which John is an argument ${ }^{3}$.

The Russian "genitive modifier" (GM) construction exemplified in (4) presents similar challenges, showing a similarly diverse range of "genitive relations", with a similar range of

\footnotetext{
${ }^{3}$ An anonymous referee suggests that one should explore a possible approach on which the genitive in (3) is a complement of the lexical adjective favorite, so that genitives, when complements, would always be complements of some lexical item. That could certainly be made to work semantically, as long as the adjective favorite is always a function applying to the noun's meaning. As the referee notes, "it does complicate the syntax at first blush"; a fuller investigation might best be carried out in connection with a study of the interaction of genitives with superlative and superlative-like constructions as in John's best picture, John's first picture.
} 
relational and non-relational nouns, although there are interesting differences between English and Russian to account for as well.

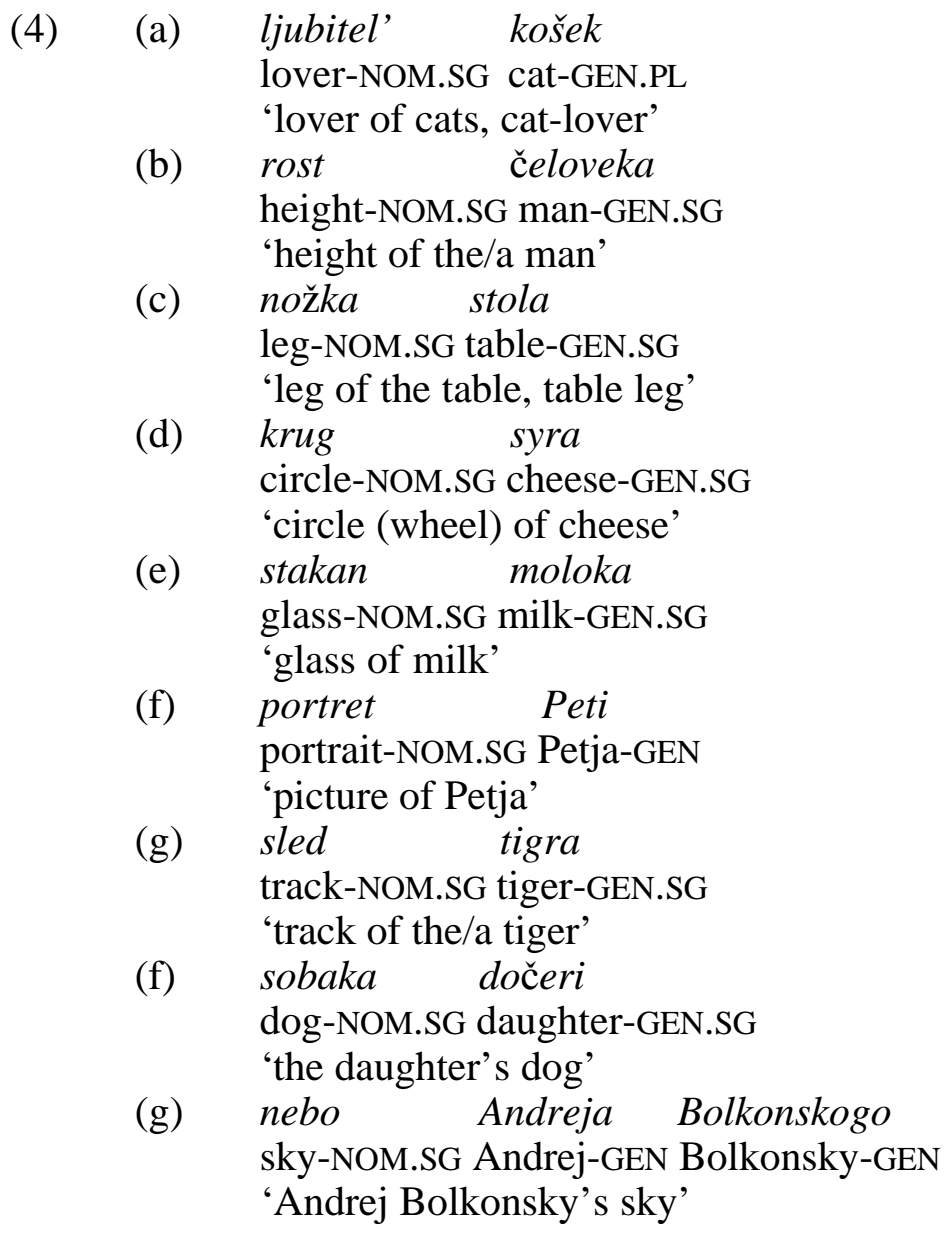

In the case of Russian, the question of whether the examples in (4) are all instances of a single construction is even more difficult than in the case of English, since the uses of the Russian genitive NP cover uses analogous to both the English Saxon genitive in (1-3) and English PPs with of + Acc.

At a descriptive level, virtually all authors who have grappled with the semantics of genitive constructions are agreed that in some cases the genitive NP seems argument-like and in other cases it seems modifier-like. The "argument" nature of at least some genitives is clearest in the case of some deverbal nouns, those called "Complex Event Nominals" by Schoorlemmer (1995), "Derived Nominals" by Babby (1997), and "process nominals" by Rappaport (1998).

To be slightly more precise about our relatively neutral assumed syntax for the first of these constructions, and for the Russian postnominal genitive construction, we represent the syntactic structure as in (5) below, a linearized form of the schematic phrase structure tree of Borschev and Partee (1999b):

(5) $\left[\begin{array}{lll}\mathrm{N} & \mathrm{N} & \mathrm{NP}_{\mathrm{GEN}}\end{array}\right]$, where $\mathrm{N}$ is a cover term for $\mathrm{N}^{0}$ and non-maximal $\mathrm{N}$-bar (Montague 1973's CN and CNP), and NP is a cover term for both $\mathrm{N}^{\mathrm{MAX}}$ and DP.

The semantic question is: do the possessive constructions [ $\left[\begin{array}{lll}\mathrm{N} & \mathrm{N} & \mathrm{NP}_{\mathrm{GEN}}\end{array}\right]$ have a 
uniform compositional interpretation? There are in principle three possibilities. (i) Assimilate all cases to the "free $\boldsymbol{R}$ " reading. That option was proposed by Hellan (1980). Partee (1983/97) argued against it on the basis of the contrast among the (c) examples in (1-3). (ii) Posit two different possessive constructions, treating "inherent $\boldsymbol{R}$ " possessives as type-raised arguments and "free $\boldsymbol{R}$ " possessives as (intersective) modifiers (Partee 1983/97). (iii) Assimilate all cases to the "inherent $\boldsymbol{R}$ " reading. This option was introduced by Jensen and Vikner (1994), and further explored in Partee and Borschev (1998), Borschev and Partee (1999a,b), and Vikner and Jensen (ms. 1999).

\subsection{Two theories of possessives.}

Partee (1983/97) proposed two distinct genitive constructions with relational and nonrelational nouns, the latter incorporating a "free relation variable $\boldsymbol{R}$ " whose value must be supplied by context. On the other hand, (a modified version of) Jensen and Vikner (1994) offers a uniform interpretation of the genitive, with coerced type-shifting of the N-bar to a relational reading when necessary. The investigation of the differences between these two approaches, in part through an ongoing dialogue which Borschev and Partee have been carrying on with Jensen and Vikner over the past two years, has led us to an appreciation that the problem of the semantics of the genitive construction(s) is a much richer domain of inquiry than we had originally imagined, and to convergence on some issues and new questions on others.

A note about notation: In what follows we use CN for a ("plain") N-bar of type <e,t> (one-place predicate, with only a "referential" $\theta$-role (Williams 1981; the R role of Babby 1997)), and TCN for a ("transitive" or "relational") N-bar of type $\langle\mathrm{e},\langle\mathrm{e}, \mathrm{t}\rangle\rangle$ like father, favorite movie.

The analysis of Partee (1983/97) posits an ambiguity in the construction, with the N-bar supplying the relation if it is relational, and with the construction supplying a "free relation variable" if the N-bar is not relational. We illustrate the postnominal genitive, as in (1b), (2b), (3b), which Partee (1983/97) analyzed as a modifier, treating the prenominal genitive in (1a), (2a), (3a) as a composition of the postnominal genitive with an implicit definite determiner.

Postnominal genitive (of John's): combines with CN or TCN to make a CN.

When a genitive NP combines with a plain $\mathrm{CN}$, type $\langle\mathrm{e}, \mathrm{t}\rangle$ : the construction provides a "free $\boldsymbol{R}$ ", a variable of type <e, <e,t>> which we write as $\boldsymbol{R}_{i \text {. }}^{4}$

(6) of John's: $\quad \lambda \boldsymbol{P} \lambda \boldsymbol{x}\left[\boldsymbol{P}(\boldsymbol{x}) \& \boldsymbol{R}_{i}(\mathrm{John})(\boldsymbol{x})\right]$

team of John's: $\quad \lambda x\left[\operatorname{team}(\boldsymbol{x}) \& \boldsymbol{R}_{i}(\mathbf{J o h n})(x)\right]$

When a genitive NP combines with a TCN, type $\langle\mathrm{e},\langle\mathrm{e}, \mathrm{t}\rangle\rangle$, the TCN provides its “inherent $\boldsymbol{R}$ ”.

(7) of John's: $\quad \lambda \boldsymbol{R}[\lambda \boldsymbol{x}[\boldsymbol{R}(\mathbf{J o h n})(x)]]$ or equivalently, $\lambda \boldsymbol{R}[\boldsymbol{R}(\mathbf{J o h n})]$ teacher of John's: $\lambda x[$ teacher(John)(x)]]

\footnotetext{
${ }^{4}$ As with the use of free variables like $\boldsymbol{x}_{\boldsymbol{i}}$ to represent pronouns used without linguistic antecedent, we assume as a felicity condition on the use of free $\boldsymbol{R}_{\boldsymbol{i}}$ that the context should make it sufficiently clear to the hearer what particular relation the speaker has in mind.
} 
Jensen and Vikner (1994) propose that an analysis which incorporates coerced typeshifting in the sense of Partee (1987) should be able to do without two separate rules for the genitive. They present an alternative analysis, building on the framework of Pustejovsky (1993, 1995): the genitive must always combine with a relational common noun (phrase), coercing a one-place predicate noun to a two-place relational meaning ("team" to an appropriate sense of "team-of"). Their analysis corresponds to the "inherent $\boldsymbol{R}$ " case of Partee (1983/97), and with a relational noun like teacher the two analyses agree. The difference arises with a plain one-place $\mathrm{CN}$ like chair or team, which on their analysis is coerced to a TCN interpretation. Jensen and Vikner follow Pustejovsky in appealing to the qualia structure of the lexical entry to guide the coercion, so that for instance the telic role of chair ("chairs are to sit in") licenses the shift of $\mathrm{CN}$ chair to TCN chair illustrated below.

$$
\begin{array}{ll}
\text { CN chair: } & \lambda x[\operatorname{chair}(x)] \\
\text { TCN chair: } & \lambda y \lambda x[\operatorname{chair}(x) \& \operatorname{sits-in}(x)(y)]
\end{array}
$$

Initially we had some important differences with Jensen and Vikner concerning the degree to which lexical meaning drives coercion. In their current work and our most recent published work, we are agreed that on the most general version of their approach, the genitive construction should always demand a TCN to combine with, and if it finds instead a CN it will coerce it by whatever means are available and "natural", sometimes lexical, sometimes pragmatic. (We make a less sharp distinction between lexically and contextually supplied shifted meanings than Jensen and Vikner do, because of the outlook on the integration of information from lexical and other sources described in Partee and Borschev 1998, Borschev and Partee 1998.) A "pragmatic" coercion is seen as shifting the noun to a relational reading that incorporates the "free relation variable" of Partee (1983/97) into the shifted noun meaning.

\section{(9) $\quad$ TCN team: $\quad \lambda y \lambda x\left[\operatorname{team}(x) \& R_{i}(x)(y)\right]$}

As in Partee's analysis, a felicitous use of an expression with a free variable requires that the context make a particular choice of value for the variable salient. Partee and Borschev (1998) propose extensions to Jensen and Vikner's coercion approach to cover also the "contextual" cases, and point to a need for more fine-grained coercion principles to cover phenomena involving the relational adjective favorite and the difference in "most likely relation" in the interpretation of examples like John's movie and John's favorite movie.

One main difference between the two approaches is then in where a "free relation variable" is added in a case where context is driving a pragmatically based coercion. Let's suppose that team of Mary's is such a case.

(10) Jensen and Vikner:

$\begin{array}{ll}\text { of Mary's: } & \lambda \boldsymbol{R}[\lambda \boldsymbol{x}[\boldsymbol{R}(\operatorname{Mary})(\boldsymbol{x})]] \\ \text { (shifted) team: } & \lambda y\left[\lambda x\left[\operatorname{team}(\boldsymbol{x}) \& \boldsymbol{R}_{i}(\boldsymbol{y})(\boldsymbol{x})\right]\right] \\ \text { team of Mary's: } & \left.\lambda x\left[\operatorname{team}(\boldsymbol{x}) \& \boldsymbol{R}_{i}(\operatorname{Mary})(\boldsymbol{x})\right]\right]\end{array}$

(11) Partee (1983):

$\begin{array}{ll}\text { of Mary's: } & \lambda \boldsymbol{P} \lambda \boldsymbol{x}\left[\boldsymbol{P}(\boldsymbol{x}) \& \boldsymbol{R}_{i}(\operatorname{Mary})(\boldsymbol{x})\right] \\ \text { (non-shifted) team: } & \operatorname{team} \\ \text { team of Mary's: } & \left.\lambda \boldsymbol{x}\left[\operatorname{team}(\boldsymbol{x}) \& \boldsymbol{R}_{\boldsymbol{i}}(\operatorname{Mary})(\boldsymbol{x})\right]\right]\end{array}$


The final result is the same; but for Jensen and Vikner the free relation variable comes in as part of the meaning of the shifted noun, while for Partee (1983/97) it comes in as part of the meaning of the genitive construction itself. Does this difference in "where" the free relation variable is situated ever make a detectable difference? Yes.

Partee and Borschev (1998) give an empirical argument in favor of Jensen and Vikner's approach, based on an analysis of the example Mary's former mansion, suggested to us by Norvin Richards (p.c.). The argument rests on four assumptions, as spelled out in (12) below.

(12) Assumptions:

i) mansion is lexically a 1-place noun.

ii) former is an endocentric modifier, lexically a $\mathrm{CN} / \mathrm{CN}$, shiftable to a TCN/TCN. former as $\mathrm{CN} / \mathrm{CN}$ : former monastery, former dancer.

former as TCN/TCN: former owner, former friend.

iii) The "free relation" variable in this case has as one of its most salient values something like "owns" or "lives in".

iv) Mary's former mansion has two readings: "Reading A": a former mansion (perhaps now just a ruin) that is (now) Mary's. I.e., now Mary's, formerly a mansion; and "Reading B": something that was formerly Mary's mansion; it may still be a mansion, but it's no longer Mary's.

On the Partee (1983/97) account, there is no motivation for any type-shifting to occur, and the "free relation" "owns" will be introduced with the possessive Mary's, after former has combined with mansion. This means that the free relation ("owns") in the interpretation of the possessive Mary's will never be under the scope of former. As a result, Partee (1983/97) can derive Reading A above, but not Reading B. Tree (13) shows the compositional structure of Mary's former mansion on the account of Partee (1983/97).

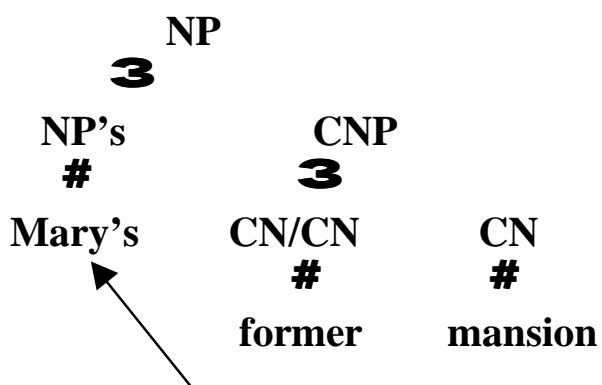

free $\boldsymbol{R}$ introduced here

But Jensen and Vikner's account, with coercion of $\mathrm{CN}$ to TCN, does provide derivations for both readings, which Partee's account cannot. For Jensen and Vikner, Mary's coerces former mansion to a relational TCN. Given our assumptions, there are two ways that former mansion could shift to a TCN.

i) Initially leave mansion as a $\mathrm{CN}$, treat former as $\mathrm{CN} / \mathrm{CN}$, combine them to form a $\mathrm{CN}$, as on Partee account; then shift that $\mathrm{CN}$ to a TCN, bringing in the free variable at that stage to get the 
shifted meaning of former mansion shown below in (14):

$$
\left.\lambda y\left[\lambda x[\text { former(mansion })(x) \& R_{i}(y)(x)\right]\right]\left[R_{i}:\right. \text { “is owned by"] }
$$

This corresponds to Reading A above, with the free $\boldsymbol{R}$ introduced at the point where the CNP shifts to become a TCNP. The compositional structure would be almost identical to that in tree (13), differing only in "where" the free $\boldsymbol{R}$ is introduced.

ii) Or shift mansion to a TCN, and former to a TCN/TCN, combine them to form a TCN as shown below in (15):

(15) $\lambda y[\lambda x[$ former(mansion-of $)(x)(y)]]$, where mansion-of is an abbreviation for $\lambda y\left[\lambda x\left[\operatorname{mansion}(x) \& R_{i}(y)(x)\right]\right]$

This corresponds to Reading B above, with compositional structure as in (16) below.

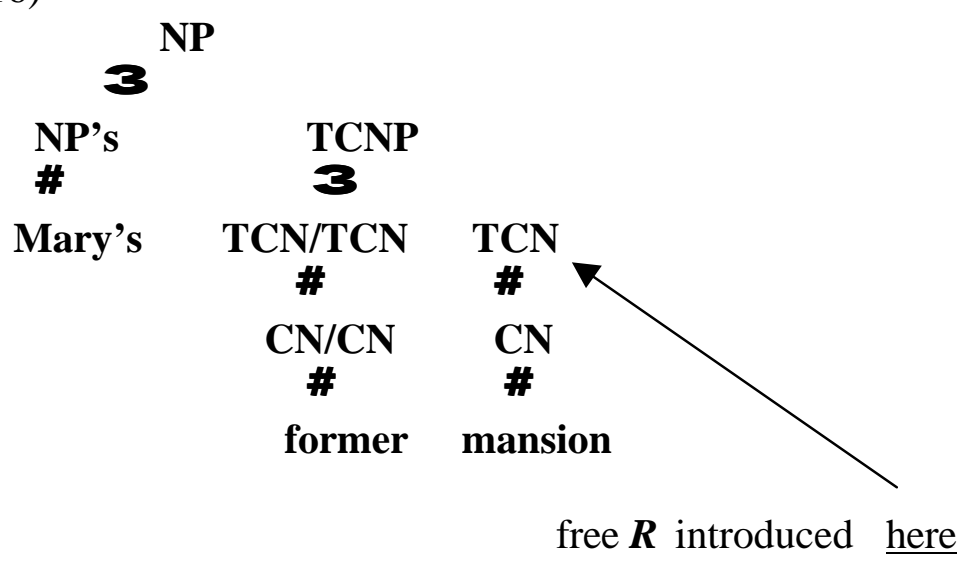

We assume that both of these ways of coercing the phrase former mansion are structurally available; different choices of lexical items or different contexts may favor one over the other, but since both are consistent with all the principles that we are aware of, the Jensen and Vikner approach successfully predicts the ambiguity and therefore has a clear empirical advantage over the Partee (1983/97) approach ${ }^{5}$.

\section{Predicate possessives: a problem for the "one genitive" approach?}

In spite of the theoretical appeal of the "one genitive" approach and its ability to solve the problem of Mary's former mansion, we are still not convinced that it is correct. One of our main worries concerns predicate possessives. We earlier observed that predicate possessives seem to favor "free $\boldsymbol{R}$ " interpretations; and predicate possessives are not in a structural argument position

\footnotetext{
${ }^{5}$ An alternative analysis of the ambiguity, based on different assumptions which we do not share, has since been offered by Larson and Cho (1999).
} 
unless one posits an empty head noun accompanying all predicate possessives. Both of these factors support the treatment of predicate possessives in Partee (1983/97) as type <e,t>, "free $\boldsymbol{R}$ " only. There the predicative John's was interpreted as $\lambda \boldsymbol{x}\left[\boldsymbol{R}_{i}(\mathbf{J o h n})(\boldsymbol{x})\right]$. The modifier-type postnominal genitive of John's of Partee (1983/97), given in (6) above, which combines with a plain $\mathrm{CN}$, amounts simply to intersective modification of the noun by this predicate possessive. And if some possessives can occur as basic <e,t> predicates, that would suggest that when those same possessives occur inside the NP, they are basically modifiers, and not arguments, returning us to the distinction posited in the earlier Partee (1983/1997) approach.

If there are no possessives that demand a treatment as basic type $\langle e, t>$ predicates, that would be an argument in favor of treating all 'modifier possessives' occurring inside an NP within the "one genitive" approach of Jensen and Vikner. That can be done on their approach by type-shifting the head CN or CNP into a relational reading incorporating the free $\boldsymbol{R}$, so that it then takes the possessive term as an argument. But if we find in some languages that there are systematic differences in form and/or interpretation between certain genitives/possessives that occur only NP-internally and others that occur both predicatively and NP-internally, that would present a serious challenge to the "one genitive" approach, at least for those languages.

But the issue is empirically complex for at least two reasons: (i) there may be independent reasons (syntactic or morphological) why some kinds of possessives (e.g. Russian genitives) cannot occur as predicates; (ii) and some predicate possessives may be elliptical full NPs; it is not always easy to tell. Much of what follows is concerned with the latter problem.

In the following sections, we look at evidence about predicate possessives in English, Russian, German, and Polish. The evidence supports the idea of two semantically different kinds of possessives, with some forms, such as English Saxon genitives, used for both. One kind are argument possessives, which fit the Jensen and Vikner analysis; these occur in construction with a relationally interpreted noun (or with an adjective like favorite plus a noun). Argument possessives do not occur in type $\langle\mathrm{e}, \mathrm{t}\rangle$, so when they occur alone, they are interpreted as elliptical $\mathrm{NPs}^{6}$ with a relational noun implicitly understood. The Russian genitive appears to be of this type, and we consider the Jensen and Vikner analysis correct for the Russian genitive construction. The other kind are true predicative possessives, basically of type $\langle\mathrm{e}, \mathrm{t}\rangle$, interpreted approximately as in the corresponding analysis of Partee (1983/97), but with the "free $\boldsymbol{R}$ " preferentially interpreted as some kind of "possession" or "control". To represent the way this distinction differs from the original distinction of Partee (1983/97), we will stop referring to the "free $\boldsymbol{R}$ " and refer instead to $\boldsymbol{R}_{\boldsymbol{P}}$ oss. When this kind of possessive occurs inside an NP, it is a modifier rather than an argument. We believe that the Russian prenominal possessive forms discussed in Section 2.2 are of this type. Since the English Saxon genitives, as well as possessive pronouns in all four of the languages looked at here, have both uses, we conclude that the "one genitive" approach cannot be correct for those constructions.

But if we do conclude that in English, for instance, there is a distinction to be made between argumental and modifier constructions both expressed by Saxon genitives like prenominal John's, we are left with a puzzle concerning the large proportion of cases which could seemingly be analyzed either way: are they all "ambiguous"? We will return to this puzzle, which remains open, in Section 3.

\footnotetext{
${ }^{6}$ We use the term "elliptical NP" for occurrences of bare John's or mine, etc., when they occur in NP positions and are interpreted as if a noun were present, without intending to take sides between a deletion approach and an interpretive approach to such ellipsis.
} 


\subsection{Predicate possessives in English.}

The nature of predicate possessives is less clear in English than in some other languages. It is difficult to be sure whether an apparent predicate possessive like John's in (1c), repeated below, is a simple one-place predicate with an $\boldsymbol{R}_{\boldsymbol{P O S S}}$ or "possession" reading, or is an 'argument genitive' occurring as part of an elliptical NP, i.e. with John's implicitly in construction with another occurrence of team.

\section{(1c) That team is John's.}

In Stockwell, Schachter and Partee (1973), it was asserted that predicate possessives as in (1c) allow only a "free $\boldsymbol{R}$ " reading, but that conclusion, maintained in Partee (1983/1997) and in Partee and Borschev (1998), was probably based on too small a sample of data and not enough careful examination of possibilities. So while (17a,b) are indeed bad, (17c) (example from Ash Asudeh, p.c.) seems to be able to get a relational reading all right. And (17d,e) (from Ekaterina Rakhilina, p.c.) together with the badness of (17f) strongly support the hypothesis that there is something wrong with the subject in $(17 \mathrm{a}, \mathrm{b})$, not with the unavailability of a suitable interpretation for the predicate possessive as hypothesized by Stockwell et al (1973).
(a) *That father is John's.
(b) *That favorite movie is John's.
(c) That teacher is John's.
(d) His [pointing] father is also John's.
(e) Dad's favorite movie is also mine.
(f) *That father is John's father.

The good examples in (17), namely $(17 \mathrm{c}, \mathrm{d}, \mathrm{e})$, all have predicate possessives that may be interpreted as elliptical NPs ${ }^{7}$ : John's teacher, John's father, my favorite movie. The bad examples $(17 \mathrm{a}, \mathrm{b}, \mathrm{f})$ all have intrinsically relational head nouns (or common noun phrase in the case of $17 \mathrm{~b}$ ) that have to be interpreted non-relationally in the subject but relationally in the predicate, assuming that $(17 \mathrm{a}, \mathrm{b})$ have elliptical predicate possessives ${ }^{8}$. The head noun in the subject in examples $(17 \mathrm{a}, \mathrm{b}, \mathrm{f})$ must shift to a non-relational reading in order to be compatible with the demonstrative determiner that; with such strongly relational expressions as father and

\footnotetext{
${ }^{7}$ We thank our anonymous referee for pointing out that in Dutch, the predicate possessive in example (17c) is even more clearly an elliptical NP than in English, and that Dutch furthermore is a language which clearly distinguishes elliptical from non-elliptical predicate possessives. In Dutch, in the rendition of $(17 \mathrm{c})$, the d-word die, signalling the presence of nominal structure, is obligatory, as shown in (i).

(i) Die docent is *(die) van Jan. That teacher is *(that) of Jan 'That teacher is Jan's.'

By contrast, in (ii) both options are possible.

(ii) Die auto is (die) van Jan. That car is (that) of Jan 'That car is Jan's.'

${ }^{8}$ In fact, if the predicate possessive in (17a) is not understood as elliptical for John's father, the sentence is wellformed but requires a strong context that can both support a one-place predicate reading of father and some kind of 'free' or 'possessive' relation in the interpretation of John's. A possible scenario could be a gathering of fathers and daughters and a team of reporters (including John) who among them are supposed to interview all the fathers and all the daughters. Similar remarks apply to (17b).
} 
favorite movie, it is not easy to construe them non-relationally, and a strong context is required to interpret the subject phrases at all. It may be that there is a restriction (perhaps a processing restriction) on shifting an expression "away from" its basic meaning and then "back again" (The "bad" sentences are probably indeed not 'ungrammatical', but are nearly impossible with respect to the intended readings 'John's father', etc..) In the good examples (17d,e) we have the relational readings of the head noun (phrases) in both the subject and the (elliptical) predicate. And the relevant difference between the good (17c) and the bad (17a) may be that unlike father, teacher is lexically supplied with equally salient and closely related relational and non-relational readings, so that one wouldn't have to 'suppress' the relational reading by shifting in order to interpret teacher in the subject NP non-relationally..

The data above, reinforced by the Dutch data mentioned in footnote 7, strongly suggest that predicate possessives may sometimes be "elliptical" NPs or "Determiner-only" NPs. And if all bare possessives in all languages could be interpreted as elliptical NPs, then predicate possessives would not pose a problem for the "one-genitive" analysis; the difference between possessive or genitive forms that can and that cannot occur "bare" as predicates would simply reflect constraints on NP ellipsis.

But we believe that not all predicate possessives are elliptical.

We do not have conclusive arguments for English; there are several complicating factors, including problems in the analysis of copular sentences. We briefly mention here some data that we consider relevant, but rather than trying to build any arguments based on English, we will then turn to other languages where the structures in question can be identified more clearly.

There are some uses of "bare" mine, yours, John's, etc., that occur in argument positions that are otherwise occupied by full NPs of type e, as in (18). We take this as clear evidence that bare possessive pronouns or Saxon genitives do occur as elliptical NPs. ${ }^{9}$ (In Russian, for instance, the same is possible with possessive pronouns but not normally with bare genitive NPs.)

Mine is over there. John's is over here. Sue already took yours and Mary's.

There are postcopular uses as in (19) where the possessives seem very much like inverted elliptical subjects, arguably of type e although perhaps of type $\langle e, t\rangle$. The debate relates to the problem of "inversion around $b e$ " and the types of NPs in apparent "inversion" sentences discussed in Williams (1983), Partee (1986), Moro (1997), Heycock and Kroch $(1998,1999)$, Partee (1999a).

(19) (a) Some of the most interesting results were John's.

(b) One of the most interesting suggestions was John's.

(c) Another proposal we will have to consider is Sara's.

Examples (20-22) below seem to us to be candidates for genuinely predicative possessives that are not elliptical full NPs, but we have no really convincing structural arguments for making the distinction in English, so our hypothesis that these are predicative rather than

\footnotetext{
${ }^{9}$ See Stockwell, Schachter and Partee (1973) for an analysis of such ellipsis and its relation to the occurrence of the pro-CNP one $(s)$ in transformational terms. In this paper we are implicitly assuming that possessive pronouns like my/mine have the same kind of semantic analysis as the Saxon genitive John's, with the morphological alternation between my and mine, etc., attributable to surface syntactic factors which we can safely ignore (see Stockwell, Schachter and Partee (1973).)
} 
elliptical is based so far on semantic intuitions and translation possibilities into languages where the distinction seems clearer.

(20) The house, the barn, and the land are finally ours and ready to move into.

(21) It's already/now/ finally/ almost ours.

(22) Anything we find on this land is John's.

Rather than try to support our intuitions about the English examples, we turn to some languages where we have found some syntactic and/or morphological distinctions that provide evidence for a distinction between modifier possessives and argument possessives.

\subsection{Russian prenominal possessives vs. genitives.}

In Russian, possessive pronouns and the normally prenominal quasi-adjectival possessive forms can occur in predicate position but genitive NPs cannot ${ }^{10}$. This suggests that Russian genitive NPs may always be argument-like, and that the Jensen \& Vikner uniform analysis with coercion of CNs to TCNs (extended to Russian in Borschev and Partee 1999a,b) is correct for the Russian genitive construction. It also suggests that the Russian prenominal possessive forms are at least sometimes modifier-like, and the same for the possessive pronouns. (Evidence of ambiguity of the roles of the possessive pronouns is in Section 2.4.)

The Russian prenominal possessive construction studied by Koptjevskaja-Tamm and Šmelev (1994) and by Babyonyshev (1997) is illustrated in (23) and the genitive construction in (24).

Petin stul

Petja-POSS-M.SG. chair-M.SG.

'Petja's chair.'

(b)

Mamin portret

Mama-POSS-M.SG. portrait-M.SG.

(a)

'Mama's portrait.'

stul Peti

chair-M.SG. Petja-GEN.SG.

'Petja's chair.'

(b)

portret mamy
portrait-M.SG. Mama-GEN.SG.
'Mama's portrait.'

In these examples, both constructions can be used in describing the same range of cases; the possible relations of Petja to the chair or of Mama to the portrait are as various as with the English prenominal genitive. But the meanings do not "feel" identical. In the possessive construction in (23), we would like to claim (as did Schoorlemmer 1995) that the possessive Petin, mamin acts as a modifier of the head noun. We believe that the prototypical interpretation of the possessive modifier is indeed 'possession' (of the object denoted by the head noun, by the (animate) entity denoted by the noun in the possessive form.) To maintain such a claim, it seems that 'possession' must be understood in a broadly extended sense to apply to a diverse range of relations; see Heine (1997). Thus in example (23b), possession may be possession proper, 'authorship', or the relation of 'being portrayed'. But the possibility of expanding the sense of

\footnotetext{
${ }^{10}$ There are exceptions to the statement that genitives can never occur predicatively; these require further study. But both traditional grammars and native speakers seem agreed that the statement is basically correct.
} 
'possession' is evidently not unlimited. Thus 'murderer of Petja' can be expressed in Russian by (25a) but not by (25b).
(a)
ubijca
Peti
murderer-M.SG. Petja-GEN.SG.
(b)
'Petja's murderer' (murderer of Petja)
Petin ubijca
Petja-POSS-M.SG. murderer-M.SG.
\# 'Petja's murderer' [ok only as e.g. 'a murderer Petja has hired']

In the genitive construction in (24a), we analyze Peti as an argument of the relation which connects it to stul. In the given case, the most salient relation could alternatively be seen as some kind of possession as well; but 'possession proper' is not the prototypical interpretation for the genitive construction. The range of possible relations expressed with a genitive is extremely broad (cf. Knorina 1985, 1988, 1990, 1996, Borschev and Knorina 1990, Partee and Borschev 1998, Borschev and Partee 1999a,b).

While this data is not completely conclusive, it supports the hypothesis that the Russian genitive construction is correctly analyzed as uniformly argumental, i.e. that Jensen and Vikner's approach to English genitives is correct instead for Russian genitives. And we believe that the Russian prenominal "adjectival" possessives are basically modifiers, with the "free" $\boldsymbol{R}_{\boldsymbol{P O S S}}$ as the core of their meanings (see the analysis in (31) below for German). But the high overlap in possible interpretation of the two constructions, as illustrated in (23) and (24), is an example of the puzzle mentioned at the end of the introduction to Section 2, to which we return in Section 3.

\subsection{German possessive pronouns.}

Tony Kroch (p.c.) suggested looking for languages that would given evidence from agreement behavior as to whether predicate possessives are more like simple (adjectival) predicates or more like full NPs. Sten Vikner (p.c) observed that German is a language that gives some evidence: Predicate adjectives in German do not agree with subjects, but predicate possessives $d o$, suggesting that predicate possessives are indeed more like elliptical NPs than like simple $<e, t>$ predicates $^{11}$.
Diese Bücher sind alt/*alte.
These-N.PL books- N.PL are old/*old- PL
Diese Bücher sind meine/*?mein
These-N.PL books are mine- PL/*mine

This would suggest that the "one genitive" approach may be correct for German, if all apparent predicate possessives give morphological evidence of being elliptical NPs.

\footnotetext{
${ }^{11}$ Further evidence that these predicate possessives are elliptical NPs was provided by Sigrid Beck and Irene Heim (p.c.): the possessive pronoun in (27) can be followed by adjectives (i.e. there can be ellipsis of just the head noun), while the adjective in (26) and the adjective-like possessive pronoun in (28b) cannot be.

(i) Dieser Bücher sind meine alte.

These-n.pl. book-n.pl are my-n.pl. old-n.pl.

'These books are my old ones.'

(ii) * Dieser Bücher sind teuer neu(e).

These-n.pl. book-n.pl. are expensive new

'These books are expensive new ones.'
} 
But it was further observed by Hans Kamp (p.c.) and others that actually, the nonagreeing form can sometimes be used. It is used only in "standard" German, not in colloquial German, and it has an "archaic" flavor. Most interestingly, it seems that there are semantic differences between the agreeing and the non-agreeing predicate possessive, and if this data stands up, it is extremely interesting.

(28) (a) Diese Bücher sind meine: can be any relation.

(b) Diese Bücher sind mein: (archaic) "Possession" only. These- N.PL books- N.PL are mine (no agreement)

Further examples are given in (29) and (30). A newly naturalized citizen might say (29a), but (29b) suggests a conqueror is speaking. Any relation is possible in (30a), with the most likely possibility being the parent-child, but (30b) suggests a custody fight, i.e. a dispute about who is to be in 'possession' of the children. In other words,

(a) Das Land ist (jetzt) meins.

The-N.SG land-N.SG is (now) mine-N.SG

(b) Das Land ist jetzt mein.

The-N.SG land- N.SG is now mine

Die Kinder sind meine.

The children are mine-PL

(b) Die Kinder sind mein.

The children are mine.

In all of (28b), (29b), (30b), the form which shows absence of agreement in the way a predicate adjective would is limited in its interpretation to "possession". In other words, the form in which the possessive pronoun appears to be a simple predicate of type $\langle e, t>$ is interpreted in terms of a relation that appears to be associated with the possessive construction itself rather than with the semantics of any governing noun.

In contrast, the forms which appear to be elliptical NPs have a range of interpretations including possession but also including relations typical of 'argument' genitives, where the relevant relation is determined ${ }^{12}$ principally by the noun to which the genitive supplies an argument. Typical choices for the 'genitive relation' for the 'argument' genitive interpretations in (28a), (29a), (30a) might be authorship, citizenship, and the parent-child relation, respectively.

Of course "possession" itself can have metaphorical extensions, so the "possession" cases do not always have to be about ownership in a literal sense. But if these distinctions are correct, this is important evidence for the idea of two distinct genitives.

So we are now inclined to believe that some predicate possessives really are plain $\langle\mathrm{e}, \mathrm{t}\rangle$ predicates, and that those have just a possession/control reading, which we take to be the

\footnotetext{
${ }^{12}$ Recall from the discussion in Section 1 that the "genitive relation" in the case of an "argument genitive" may either be intrinsic to the lexical semantics of the noun, as with father, teacher, or may result from shifting the noun from a simple $\mathrm{CN}$ to a relational TCN by incorporating a lexically or contextually salient relation. In order to find examples that will support both 'possessive' and 'argument' genitives, we have looked for nouns for which both possibilities are reasonable, i.e. nouns which can easily be construed either relationally or as plain nouns denoting 'possessable' entities. Not all nouns can be expected to support both readings, and not all speakers will find both possibilities equally reasonable in the examples we have given in this and the following section.
} 
semantics of the <e,t> possessive, as shown in (31) below. And other predicate possessives may be elliptical NPs, and their interpretation may have the full range of possibilities that would be displayed by a full NP with a prenominal genitive occurring in such a position. (Note that a full NP may itself have meanings of types e, $\langle e, t\rangle$, or $\langle\langle e, t\rangle, t\rangle$, depending on both its internal makeup and the position in which it occurs, so the study of the full range of meanings of bare possessives as elliptical NPs needs more study.)

$$
\left[J_{o h n}\right]_{\mathrm{PRED}}: \lambda \boldsymbol{x}\left[\boldsymbol{R}_{\text {POSS }}(\mathbf{J o h n})(\boldsymbol{x})\right] \quad \text { type: }\langle\mathrm{e}, \mathrm{t}>
$$

\subsection{Russian and Polish possessive pronouns.}

In Russian, in the past tense, predicate nominals may be in the Instrumental case, particularly when indicating temporary relations. Babby (1973), Siegel (1976) and others have used case and other agreement behavior to argue that some predicative adjectives are elliptical NPs and others are simple APs. The following data may provide a basis for distinguishing among predicate possessive pronouns that are and are not elliptical NPs.

$$
\text { Éta strana byla kogda-to moej }
$$

That-F.NOM.SG country-F.NOM.SG was-F.SG once my-F.INSTR.SG 'That country was once mine' ['possession' or citizenship]
Éta
strana
byla
kogda-to moej

That-F.NOM.SG country-F.NOM.SG was-F.SG once my-F.INSTR.SG stranoj

country-F.INSTR.SG

'That country was once my country' ['possession' or citizenship]

Éta strana byla kogda-to moja

That-F.NOM.SG country-F.NOM.SG was-F.SG once

my-F.NOM.SG

'That country was once mine' ['possession' only]

(b)

*Éta strana byla kogda-to moja
That-F.NOM.SG country-F.NOM.SG was-F.SG once my-F.NOM.SG
strana
country-F.NOM.SG
'That country was once my country'

A full predicate nominal is impossible in the nominative in the context of (33b), and in the same context, a nominative predicate possessive pronoun can be interpreted only as a possessive, not as an 'argument' genitive (even with a seemingly 'free' relation.) Thus the predicate possessive in (33a) cannot reasonably be analyzed as an elliptical NP, but must be a simple $<\mathrm{e}, \mathrm{t}>$ predicate, and it is this occurrence of the predicate possessive that unambiguously denotes "possession". This data is similar to the German data, supporting the idea that there is a 'possessive' predicate of type <e,t> instantiated at least by some possessive pronouns in German and Russian and possibly also by some predicative "NP's" forms in English, distinct from other cases of predicate possessives which are elliptical full NPs and in which the possessive may be an argument of an implicit relational noun.

Wayles Browne (p.c.) suggested that we should get data on Polish, because in Polish NP be - NP requires Instrumental on the predicate NP, whereas in Russian the predicate NP may or may not be Instrumental. And in Polish NP - be - Adj requires Nominative on the Adjective, 
whereas in Russian the predicate AP may be 1) short-form Adjective, 2) long-form Nominative Adjective, or 3) long-form Instrumental Adjective.

The corresponding Polish data are as follows ${ }^{13}$.

(a)

(b)

(a)

(b)

(c)

\author{
Ten \\ kraj \\ $b y^{3}$ \\ kiedys' moim. \\ That-M.NOM.SG country-M.NOM.SG was-M.SG once my-M.INSTR.SG \\ 'That country was once mine' ['possession' or citizenship] \\ Ten kraj by ${ }^{3}$ kiedys' moim \\ That-M.NOM.SG country-M.NOM.SG was-M.SG once my-M.INSTR.SG \\ krajem. \\ country-M.INSTR.SG \\ 'That country was once mine' ['possession' or citizenship; citizenship \\ preferred.]
}
Ten
kraj
$b y^{3}$
kiedys' mo'j.

That-M.NOM.SG country-M.NOM.SG was-M.SG once my-M.NOM.SG 'That country was once mine' ['possession' only]
*Ten
kraj
$b y^{3}$
kiedys' $m o^{\prime} j$

That-M.NOM.SG country-M.NOM.SG was-M.SG once my-M.NOM.SG

kraj.

country-M.SG

'That country was once my country' [ungrammatical]
Ten
kraj
to $b y^{3}$
kiedys' $m o^{\prime} j$

That-M.NOM.SG country-M.NOM.SG PRT was-M.SG once

my-M.NOM.SG

kraj.

country-M.SG

'That country was once my country ${ }^{14}$ ['possession' or citizenship]

The Polish data confirm the hypothesis that when a predicate possessive pronoun allows an "argumental" reading, it is the remnant of an elliptical NP, and when it doesn't, it isn't. The "possession" reading, which seems to be emerging as the clearest case of a non-argumental, or

\footnotetext{
${ }^{13}$ Thanks to Ania £ubowicz and Anita Nowak for judgments. For (34a), Anita reports no preference for one reading or the other, while for (34b) she reports a preference for the 'citizenship' reading. Both rejected (35b) as ungrammatical; Ania suggested that it should be corrected to (35c), which she finds possibly ambiguous. Both agreed that (35a) is unambiguously "possession" only, whereas (34a) allows either reading. The basic judgments given above in the text for $(34 a, b)$ and $(35 a, b)$ were further confirmed by Janusz Bien, Bozena Cetnarowska (and by a substantial majority of a group of 12 students of hers), Bozena Rozwadowska, Piotr Banski, and Joanna Blaszczak, to all of whom we are grateful. Janusz Bien noted that similar contrasts can be gotten, possibly even more clearly, with the Polish dom, which can mean either 'house' (a plain $\mathrm{CN}$ ) and 'home' (a TCN). Bozena Rozwadowska reports that when you use the noun portret 'portrait', the nominative adjectival predicate $\operatorname{moj}$ (as in (35a)) gives a normal sentence with a 'possession' sense: 'That portrait was once mine'. But when you use the instrumental moim as in (34a), the result seems nonsensical because it seems to have to mean 'that the person in the portrait was me some time ago but that now it is somebody else.' That judgment suggests that the instrumental form requires the argument reading; I have no explanation for why the possession reading is not an alternative possibility here as well.

${ }^{14}$ There was a problem about whether or not to include this sentence in the paper. The argument is clear and simple without it, and for non-Polish speakers, including it is simply a puzzling distraction, as our anonymous referee pointed out. However, when we present our work without it to audiences that include Polish speakers, someone always brings it up, so our compromise is to include it just to show that we are aware of its existence but to leave for further study the question of its grammatical and topic-focus structure.
} 
modifier, reading, can show up either in a remnant of an NP or as a bare $\langle e, t\rangle$ predicate. This reinforces the idea that a possessive inside an NP can be either an argument or a modifier. But a possessive which is an $\langle\mathrm{e}, \mathrm{t}\rangle$ predicate in a predicational construction cannot be an argument, presumably because it is not in construction with a head of which it could be the argument. ${ }^{15}$

\section{Conclusion and remaining puzzles.}

The examination of predicate possessives ${ }^{16}$ in section 2 leads us to the conclusion that not all predicate possessives are remnants of elliptical NPs, and that there do exist $\langle\mathrm{e}, \mathrm{t}\rangle$ predicate possessives distinct from argument possessives. When possessives which are identified as <e,t> possessives on the basis of their behavior in predicate position are also found inside an NP, it is therefore natural to assume that they are acting as modifiers, like other $\langle\mathrm{e}, \mathrm{t}\rangle$ predicates (intersective adjectives, relative clauses, locative and other prepositional phrases). Some possessives seem to occur only in NPs and these are therefore reasonably regarded as arguments, or arguments that have been type-lifted to become modifier-like functors (which we also call 'argument genitives' or 'argument possessives' insofar as they directly or indirectly saturate an argument position in the relational $\mathrm{CN}$ or CNP). Argument genitives may be in construction with the head $\mathrm{N}$ or with a modified $\mathrm{N}$ such as favorite movie or former mansion (but see footnote 3 ).

\footnotetext{
${ }^{15}$ Although it might seem self-evident that a predicate separated from a subject by a copular verb cannot function as an argument to the head noun of the subject, English sentences like This photo is of John show that the situation is more complicated and requires further investigation of the sorts of constructions Grimshaw (1990) calls 'argument adjuncts'.

${ }^{16}$ One related bit of evidence which has come to light recently and which we have not had time to explore fully enough to discuss in this paper concerns the Russian negative possessive pronoun nièej 'no one's'. Normally a negative polarity item like other Russian $n i$ - words (words corresponding to English $n$-words nothing, no one, nowhere, etc., except that Russian is a 'multiple negation' language), it occurs with and without accompanying sentential negation in the following minimal pair, for discovery and discussion of which we are grateful to Elena Paducheva and Ekaterina Rakhilina. Sentence (ib) is not considered fully acceptable by the second author.
}

(i)

(a) Éto

nièej

ne portret.

Éto

kartina.

That $[\varnothing$-COPULA] no-one's-M.SG.NOM NEG portrait-M.SG.NOM That [ $\varnothing$-COPULA] picture 'That's not anyone's portrait. That's (just) a picture.'

(b) Éto nièej portret. Ego nikto

That $[\varnothing$-COPULA] no-one's-M.SG.NOM portrait-M.SG.NOM It-M.SG.ACC no-one

ne kupil.

NEG bought

'That's not anyone's portrait. No one bought it.'

The word nièej here acts as a normal negative polarity item on its argument use in (ia); but when it occurs as a possessive modifier meaning 'belonging to no one' in (ib), it does not take the usual accompanying sentential negation ne. While a full analysis of these examples awaits further research, we hypothesize that the argument nièej in (ia) in the semantically relevant structure of the NP is governed by the (relational) noun, while the modifier nièej in (ib) expresses a predicate that has negation internal to it, and is semantically conjoined (intersected) with the noun (here a one-place predicate). Even without full analysis, such a pair would seem to further support the existence of a distinction between argument possessives and modifier possessives. 
In some languages, like Russian, it may be possible to argue for a correlation of the semantic distinction with a distinction in form: we hypothesize that the prenominal possessives are modifier possessives, while true genitives are always (possibly type-lifted) arguments ${ }^{17}$.

The clearest examples of predicative possessives seem to have meanings that relate to the notional concept of 'possession', not to the "free $\boldsymbol{R}$ " readings posited as predicative in the early work of Partee. This suggests that we should work with a different basic split: between (i) predicative or modifier readings that have a (possibly extended) meaning of "possession", a relational notion $\boldsymbol{R}_{\boldsymbol{P O S S}}$ that comes from the possessive form rather than from a noun, and (ii) 'argument' readings that involve either an inherently relational noun or a plain noun coerced to a relational reading. This is thus not exactly a return to the early Partee (1983/97) analysis, but an analysis that agrees with Partee and Borschev's extensions of Jensen and Vikner's analysis except for the recognition of a separate predicative "possessive" reading. What Partee (1983/97) analyzed as "free $\boldsymbol{R}$ " cases may be a mixture of predicative possessives of type <e,t>, acting as intersective modifiers when they occur inside an NP, and argument possessives in construction with a noun which has been coerced to a relational reading by the incorporation of some lexically accessible relation (such as 'part-whole' or 'created by') or of a salient free $\boldsymbol{R}$.

There are at least two major interrelated puzzles remaining open at this point. One is how to think about the notion of "possession" that has been appealed to here, since it is evidently extremely broad. The second, mentioned at the end of section 1, is how to think about English Saxon genitives in the light of the hypothesized split: are English genitives inside NPs ambiguous between modifier and argument? Given that Russian very often allows the same relation to be expressed either way, it would be difficult to rule out one analysis or the other of an unclear case on any semantic grounds. And for the same reason, the great semantic elasticity of interpretation shown by both constructions, this seems a very puzzling kind of "ambiguity" and very hard to get clear evidence for. In a language like English where the same form is used for both modifier and argument possessives, is one construction the dominant or default one that is used wherever there is not clear evidence for the other? Or is this just a benign instance of the fluidity of the argument-modifier shifting possibilities discussed by Dowty (1997)? Does one simply use in a given case whichever analysis requires the least type-shifting?

These issues and many others remain to be explored.

\section{References}

Babby, Leonard H. 1973 "The deep structure of adjectives and participles in Russian". Language 49: 349-60.

Babby, Leonard H. 1997 "Nominalization in Russian". In Formal Approaches to Slavic Linguistics: The Cornell Meeting 1995, W. Browne, E. Dornisch, N. Kondrashova, and D. Zec (eds), 54-83. Ann Arbor, MI: Michigan Slavic Publications.

Babyonyshev, M. 1997 "The possessive construction in Russian: a crosslinguistic perspective". Journal of Slavic linguistics 5: 193-233.

\footnotetext{
${ }^{17}$ We have somewhat more confidence in the conclusion that Russian genitives are always arguments than in the conclusion that Russian prenominal possessives are always modifiers; the latter claim needs further research. The history of these forms merits further investigation; Richards (1976) reports that in Old Russian, the 'possessive adjective' forms were much more common than the use of the genitive, the opposite of the situation in modern Russian, where the possessive adjectives are much more limited in their use. Her work suggests that many factors other than the semantics of the construction have been relevant through its history, and she cites examples from late Old Russian (XV-XVII c.) from Makarova (1954) of two-word proper names in which one of the words is in the genitive and the other in the possessive adjective form. Thus we recognize that we need to have caution in possibly trying to read too much semantics into the distinction between the two forms in contemporary Russian.
} 
Borschev, Vladimir.B. and Knorina, L.V. 1990 "Tipy realij i ix jazykovoe vosprijatie [Types of entities and their perception in language]". In Language of Logic and Logic of Language, 106-134. Moscow.

Borschev, Vladimir and Partee, Barbara H. 1998 "Formal and lexical semantics and the genitive in negated existential sentences in Russian". In Formal Approaches to Slavic Linguistics 6 [The Connecticut Meeting 1997], Ž. Boskoviæ, S. Franks and W. Snyder (eds), 75-96. Ann Arbor, MI: Michigan Slavic Publications.

Borschev, V.B. and Partee, Barbara H. 1999a "Semantika genitivnoj konstrukcii: raznye podxody $\mathrm{k}$ formalizacii [Semantics of genitive construction: different approaches to formalization]". In Tipologija i teorija jazyka: Ot opisanija k ob”jasneniju. K 60-letiju Aleksandra Evgen'evièa Kibrika [Typology and Linguistic Theory: from Description to Explanation. For the 60th birthday of Aleksandr E. Kibrik], E.V. Rakhilina and Y.G. Testelets (eds), 159-172. Moscow: Jazyki Russkoj Kul'tury.

Borschev, Vladimir and Partee, Barbara H. 1999b "Semantic Types and the Russian Genitive Modifier Construction”. In Formal Approaches to Slavic Linguistics [The Seattle Meeting 1998], K. Dziwirek et al. (eds), 39-57. Ann Arbor, MI: Michigan Slavic Publications.

Brown, Sue 1999 The Syntax of Negation in Russian: A Minimalist Approach. Stanford: CSLI Publications.

Dowty, David 1997 Adjunct-to-argument reanalysis in a dynamic theory of grammar: The problem of prepositions. Paper presented at the Blaubeuren Semantics Conference, University of Tübingen, March 1997.

Freeze, Ray 1992 "Existentials and other locatives". Language 68: 553-595.

Heine, Bernd 1997 Possession: Cognitive Sources, Forces, and Grammaticization. Cambridge: Cambridge University Press.

Hellan, Lars 1980 “Toward an Integrated Theory of Noun Phrases.” PhD Thesis, Trondheim University.

Heycock, Caroline and Kroch, Anthony 1998 "Inversion and equation in copular sentences". I n Papers in Linguistics 10 ， A. Alexiadou, N. Fuhrhop, U. Kleinhenz, and P. Law (eds), 71-87. B erl i n: Zentrum fuer allgemeine Sprachwissenschaft.

Heycock, Caroline and Kroch, Anthony 1999 "Pseudocleft connectivity: Implications for the LF interface level". Linguistic Inquiry 30: 327-364.

Jensen, Per Anker and Vikner, Carl 1994 "Lexical knowledge and the semantic analysis of Danish genitive constructions". In Topics in Knowledge-based NLP Systems, S.L.Hansen and H.Wegener (eds), 37-55. Copenhagen: Samfundslitteratur.

Jensen, Per Anker and Vikner, Carl 1996 "The double nature of the verb have". In LAMBDA 21 [OMNIS Workshop 23-24 Nov. 1995], 25-37. Institut for Datalingvistik, Handelshøjskolen i København.

Knorina, L.V. 1985 "Ob interpretacii genitivnyx konstrukcij [On the interpretation of genitive constructions]". [Theses of the workshop "Semiotic foundations of intellectual activity"]. Moscow, VINITI.

Knorina, L.V. 1988 "Klassifikacija leksiki i slovarnye definicii [Lexical classification and dictionary definitions]". In Nacional'naja specifika jazyka i ee otraženie $v$ normativnom slovare, J.N. Karaulov (ed.), 60-63. Moskva: Nauka.

Knorina, L.V. 1990 "Narushenija sochetajemosti i raznovidnosti tropov v genitivnoj konstrukcii [Violations of cooccurence and varieties of tropes in genitive construction]". In Contradictions and Anomalies of Text, 115-124. Moscow.

Knorina, L.V. 1996 "The range of biblical metaphors in smikhut". Moscow Linguistic Journal 3: 80-94. 
Koptjevskaja-Tamm, Maria and Šmelev, Aleksej 1994 “Alešina s Mašej stat'ja (o nekotoryx svojstvax russkix 'pritjazatel'nyx prilagatel'nyx') [Alješa and Maša's article (on some properties of the Russian 'adjectival possessives')]'. Scando-Slavica 40:209-228. Landman, Fred and Partee, Barbara H. 1984 Weak NPs in HAVE sentences. Draft abstract. Amherst, MA: University of Massachusetts.

Larson, Richard and Cho, Sungeon 1999 "Temporal adjectives and the structure of possessive DPs". In Proceedings of WCCFL 18, S. Bird, A.Carnie, J. D. Haugen, and P. Norquest (eds), 299-311. Cambridge: Cascadilla Press.

Makarova, S. Ja.1954 "Roditel'nyj padež prinadležnosti v russkom jazyke XI-XVII vv." [Genitive of possession in the Russian language of the 11th-17th centuries".] In Trudy Instituta Jazykoznanija AN SSSR III, 7-31.

Montague, Richard 1973 "The proper treatment of quantification in ordinary English". In Formal Philosophy, R.H. Thomason (ed.), 247-270. New Haven: Yale University Press, 1974.

Moro, Andrea 1997 The Raising of Predicates. New York: Cambridge University Press.

Partee, Barbara H. 1986 "Ambiguous pseudoclefts with unambiguous be". In Proceedings of NELS 16, S. Berman, J.-W. Choe, J. McDonough (eds), 354-366.

Partee, Barbara H.1987 "Noun phrase interpretation and type-shifting principles". In Studies in Discourse Representation Theory and the Theory of Generalized Quantifiers, J. Groenendijk, D. de Jongh, and M. Stokhof (eds), 115-143. Dordrecht: Foris.

Partee, Barbara H. 1983/1997 "Uniformity vs. versatility: the genitive, a case study". In The Handbook of Logic and Language, J. van Benthem and A. ter Meulen (eds), 464-470. Amsterdam: Elsevier.

Partee, Barbara H. 1999a "Copula inversion puzzles in English and Russian". In Formal Approaches to Slavic Linguistics [The Seattle Meeting 1998], K. Dziwirek et al. (eds), Ann Arbor, MI: Michigan Slavic Publications. Also to appear in UMOP 23: Issues in Semantics and its Interface, K. Kusumoto and E. Villalta (eds), Amherst: GLSA.

Partee, Barbara H. 1999b "Weak NP's in HAVE sentences." In JFAK [a Liber Amicorum for Johan van Benthem on the occasion of his 50th Birthday; CD-ROM], J. Gerbrandy, M. Marx, M. de Rijke, and Y. Venema (eds). Amsterdam: University of Amsterdam. Available: http://turing.wins.uva.nl/ j50/cdrom/

Partee, Barbara H. and Borschev, Vladimir 1998 "Integrating lexical and formal semantics: Genitives, relational nouns, and type-shifting". In Proceedings of the Second Tbilisi Symposium on Language, Logic, and Computation, R. Cooper and T. Gamkrelidze (eds), 229-241. Tbilisi: Center on Language, Logic, Speech, Tbilisi State University.

Pustejovsky, James 1993 “Type coercion and lexical selection”. In Semantics and the Lexicon, J.Pustejovsky (ed.), 73-94. Dordrecht: Kluwer.

Pustejovsky, James 1995 The Generative Lexicon. Cambridge, MA: The MIT Press.

Rappaport, Gilbert 1998 "The Slavic noun phrase". [Position paper for Comparative Slavic Morphosyntax]. $\quad$ Available: http://www.indiana.edu/ slavconf/linguistics/download.html [1999, Jan. 4]

Richards, Karen Rondestvedt 1976 "Toward a history of the possessive in literary Russian: The demise of the possessive adjective". In Papers from the Parasession on Diachronic Syntax, Chicago Linguistic Society, S.B. Steever et al. (eds), 260-73. Chicago: Chicago Linguistic Society.

Schoorlemmer, Maaike 1995 Participial Passive and Aspect in Russian. Ph.D. dissertation, OTS [Utrecht Institute of Linguistics]: Utrecht. 
Siegel, Muffy 1976 "Capturing the Russian adjective”. In Montague Grammar, B. Partee (ed.), 293-309. New York: Academic Press.

Stockwell, Robert P., Schachter, Paul and Partee, Barbara H. 1973 The Major Syntactic Structures of English. New York: Holt, Rinehart and Winston.

Szabolcsi, Anna 1994 “The Noun Phrase”. In Syntax and Semantics, Vol. 27 [The Syntactic Structure of Hungarian], F. Kiefer and K. É.Kiss (eds), 179-275. New York: Academic Press.

Vikner, Carl and Jensen, Per Anker 1999 A semantic analysis of the English genitive: Interaction of lexical and formal semantics. Ms. Copenhagen and Kolding, Denmark.

Williams, Edwin 1981 "Argument structure and morphology". Linguistic Review 1: 81-114.

Williams, Edwin 1983 "Semantic vs. syntactic categories". Linguistics and Philosophy 6: 423446. 